\title{
Management of Vascular Injury in a Vascular Center of a Developing Country
}

\author{
Quazi Abul Azad ${ }^{1}$, Aizizul Islam Khan², Abdullah Al Mamun³, Nirmal Kanti Dey \\ Sajia Sajmin Siddiqua ${ }^{5}$, Mohammad Awlad Hossain ${ }^{6}$
}

\begin{abstract}
:
In surgical practice management of vascular injuries are challenging. Vascular injuries are well addressed in developed countries but there is scarcity of vascular surgeons in developing countries like us and a large number of victims fail to reach specialist in time with consequent loss of limbs or lives. To observe the pattern and outcome of management of vascular injury in a developing country this retrospective study was conducted at the department of vascular surgery, National Institute of Cardiovascular Diseases (NICVD), Dhaka, Bangladesh. All patients with vascular injury arrived alive were included in the study. Date in terms of age, sex, cause of injury, segment of vessel involved, associated injuries, time elapsed after injury, vascular procedures done and postoperative complications were taken from records of the department and were analyzed. Out of 2174 patients with vascular injury 11 patients died at resuscitation \& 52 did not come back after referral to other hospitals for management of associated injuries.
\end{abstract}

Most of the patients were young male \& road traffic accidents was the most common cause $(91.50 \%)$. Majority $(53.60 \%)$ of the patients presented after 6 hours. Majority of the cases lower limb vessels were injured (64.05\%). Among the associated injuries combine orthopedic \& soft tissue injuries were most common (60.58\%). Among the vascular procedures antilogous venous graft (42.39\%) followed by end to end anastomosis $(27.79 \%)$ were in majority of the cases. In case of extremity vascular injury limb amputation rate was $35.40 \%$. This morbidity can be reduced by improvement of road safely measures, encouraging doctors to vascular surgery specialty and effective training of orthopedic \& general surgeons in the management of extremity vascular injury till the availability of vascular surgeons for provision of vascular services in remote areas.

Key words: Vascular injuries, Extremity, Vascular surgeon, Time elapsed after vascular injury, Developing country.

(Bangladesh Heart Journal 2021; 36(1): 32-37)

Introduction:

Injury is the leading cause of death and disability in the first four decades of life and is the third most common cause of death overall. Among the causes of injury road traffic accidents (RTA) are commonest ${ }^{1}$. In case of polytrauma about $10 \%$ patients have associated vascular injury and these causes significant mortality \& morbidity. Major uncontrolled bleeding is an important cause of preventable death in trauma victims. Peripheral arterial

1. Associate Professor (Cardiovascular Surgery), National Institute of Cardiovascular Diseases (NICVD), Sher-e-Bangla Nagar, Dhaka1207.

2. Assistant Professor (Cardiac Surgery), NICVD, Sher-e-Bangla Nagar, Dhaka-1207.

3. Assistant Professor (Vascular Surgery), NICVD, Sher-e-Bangla Nagar. Dhaka-1207.

4. Assistant Professor (Vascular Surgery). NICVD, Sher-e-Bangla Nagar, Dhaka-1207.

5. Senior Consultant (Surgery), Sarkari Karmachari Hospital, Fulbaria, Dhaka.

6. Junior Consultant (Orthopedic Surgery), 100 Bedded Zilla Hospital. Narsingdi, Bangladesh.

Address of Correspondence: Dr. Quazi Abul Azad, Associate Professor (Cardiovascular Surgery), National Institute of Cardiovascular Diseases (NICVD), Sher-e-Bangla Nagar, Dhaka-1207. Email: azadquazi1969@gmail.com

DOI: https://doi.org/10.3329/bhj.v36i1.55515

Copyright $\odot 2017$ Bangladesh Cardiac Society. Published by Bangladesh Cardiac Society. This is an Open Access articles published under the Creative Commons Attribution-NonCommercial 4.0 International License (CC BY-NC). This license permits use, distribution and reproduction in any medium, provided the original work is properly cited and is not used for commercial purposes. 
injuries are approximately $40-75 \%$ of all vascular injury. Risk factors, diagnosis and management of vascular injury depends on the vessel involved. A high degree of suspicion of vascular injury with early diagnosis \& intervention are important for optimum outcome..$^{2-4}$

Trauma including vascular injury is a national health problem in developing countries like us due to limited resource facilities with inadequate emergency health care services. Vascular injury are frequently associated with orthopedic \& complex soft tissue injury. A surgeon have to be prepared to asses these urgently and decides the best management option depending on the individual patients condition. ${ }^{5-7}$

In the field of surgery vascular injury comprises one of the most fascinating conditions. Vascular surgeon's arc trained in the management of diseases affecting all parts of the vascular system except that of the heart \& its vessels and the brain. Previously vascular surgery was a field within general surgery but now it is considered a specialty on its own right. But with limited resource facilities in developing countries and in areas \& situations lacking the availability of vascular surgeons to deal with emergency cases of vascular injury in extremities \& or the abdomen to save the life and limbs of patients- the general as well as orthopedic surgeons need to have an adequate training and good expertise in vascular surgcry. 8.9

\section{Methods:}

This retrospective study was done at the department of vascular surgery, National Institute of Cardiovascular Diseases (NICVD), Dhaka, Bangladesh from July 2017 to September 2018. Consecutive 2174 patients with vascular injury either isolated or associated with other injury presented in the emergency or outpatient department of the vascular surgery were included in this study; brought dead patients with vascular injury were excluded from the study.

Information's regarding age \& sex of patients, cause of injury, time elapsed after injury, site \& type of vascular injury, associated injury, treatment done and result of treatment including limb salvage \& complication if any were recorded from patients file, ward, operation theatre $\&$ intensive care unit registers.

Patients with extremity vascular injury whose limbs were viable (warm, positive distal pulses, $>90 \%$ oxygen saturation and intact neurological signs) with repairable soft tissues and skeletal injuries were considered salvaged. Patients with associated head injury or major orthopedic injury of extremity with unstable wounds were referred to other hospitals for neurocare and stabilization of fracture \& or dislocation site first. Patients with extremity vascular injury with acute abdomen were also referred to other hospitals for management of acute abdomen first. Data were entered into a computer and data tile was constructed. Data were decribed as percentage (\%) \& mean $\pm S D$ (standard deviation) as appropriate.

\section{Results:}

Out of 2174 patients of vascular injury of this study, 11 patients died during resuscitation and in 442 cases advised amputation of affected portion of extremity at presentation. 167 patients were referred to other hospitals for management of associated injuries as a priority basis and from them 115 patients came back for vascular injury management after treatment of associated injuries, it was advised amputation of affected part of limb in 39 cases of returned patients. But the treatment modality \& outcome of rest 52 patients those not came back were lacking. Vascular procedures were done in total 1630 patients.

Age of the patients ranged from $03-83$ years with mean age of $36.77 \pm 9.86$ years. Majority $(69.30 \%)$ of the patients were in the age group of 26 to 45 years. $93.20 \%$ of the patients were male \& $6.80 \%$ were female. Road traffic accidents was the most common $(91.50 \%)$ cause of vascular injury followed by assault (5.50\%). 46.40\% patients presented within 6 hours \& $53.60 \%$ patients presented after 6 hours following injury (Table I).

In $64.05 \%$ cases lower limb, $35.45 \%$ cases upper limb, $00.30 \%$ cases abdominal and $00.20 \%$ cases neck vessels were involved (Table II). In 2148(98.80\%) cases had associated injuries. Among the associated injuries majority $(60.58 \%)$ were combined orthopedic \& soft tissue injury (Table III). Time elapsed from injury to vascular procedures were 6 hours or less in $44.17 \%$ cases \& more than 6 hours in $55.83 \%$ cases (Table IV). Among the vascular procedures end to end anastomosis in $27.79 \%$, autologous vein interposition/patch in $42.39 \%$, PTFE graft in $03.57 \%$, ligation of bleeding vessels in $22.79 \%$ and vessel release in $3.46 \%$ cases were done (Table V). In patients with associated injuries of limb veins venous repair was done for popliteal, femoral and subclavian veins: rest of the veins were ligated. Fasciotomy were done in $37.45 \%(610)$ cases. Following vascular procedures- 548 (33.62\%) patients developed postoperative complications (Table VI). In 265 patients' amputation were advised after vascular procedures due to failed repair, graft thrombosis, sepsis, renal failure \& inadequate soft tissue coverage. In case of extremity vascular injury total $746(35.40 \%)$ patients were advised for amputation with limb salvage rate of $64.60 \%$. 
Table-I

Base line characteristics of study patients $(N=2174)$.

\begin{tabular}{|c|c|c|}
\hline Variables & Number of Patients & Percentage \\
\hline \multicolumn{3}{|l|}{ Age (in years) } \\
\hline$<15$ & 71 & 03.30 \\
\hline $16-25$ & 331 & 15.20 \\
\hline $26-35$ & 805 & 37.00 \\
\hline $36-45$ & 703 & 32.30 \\
\hline $46-55$ & 176 & 08.10 \\
\hline $56-65$ & 45 & 02.10 \\
\hline$>65$ & 43 & 02.00 \\
\hline \multicolumn{3}{|l|}{ Mean \pm SD } \\
\hline \multicolumn{3}{|l|}{ Range } \\
\hline \multicolumn{3}{|l|}{ Sex } \\
\hline Male & 2026 & 93.20 \\
\hline Female & 148 & 06.80 \\
\hline \multicolumn{3}{|l|}{ Cause of injury } \\
\hline \multicolumn{3}{|l|}{ RTA } \\
\hline Assault & 1990 & 91.50 \\
\hline Industrial accidents & 120 & 05.50 \\
\hline Explosive & 43 & 02.00 \\
\hline \multirow[t]{2}{*}{ latrogenic } & 15 & 00.70 \\
\hline & 6 & 00.30 \\
\hline \multicolumn{3}{|l|}{$\begin{array}{l}\text { Time elapsed to } \\
\text { reach hospital after } \\
\text { injury (in hours) }\end{array}$} \\
\hline$<6$ & 1009 & \\
\hline \multirow[t]{2}{*}{$>6$} & 1165 & 46.40 \\
\hline & & 53.60 \\
\hline
\end{tabular}

SD Standard deviation, RTA= Road traffic accident.

Table-II

Segments of vessel involved (N2 174).

\begin{tabular}{lcc}
\hline Variables & Number of Patients & Percentage \\
\hline Upper limbs & 771 & 35.45 \\
Subclavian & 61 & 02.80 \\
Axillary & 24 & 01.10 \\
Brachial & 245 & 11.25 \\
Radial/Ulnar & 441 & 20.30 \\
Lower Limbs & 1390 & 6405 \\
Femoral & 339 & 15.60 \\
Popliteal & 685 & 31.50 \\
Anterior Tibial/ & 366 & 16.95 \\
Posterior tibial & & \\
Abdominal (Combined & 9 & 00.30 \\
intra \& retroperitoneal) & & 00.20 \\
Neck vessels & 4 & \\
\hline
\end{tabular}

Table-III

Associated injuries among the study population $(n=2148)$

\begin{tabular}{lcc}
\hline Injury Type & $\begin{array}{c}\text { Number of } \\
\text { Patients }\end{array}$ & Percentage \\
\hline Orthopedic injury (Fracture/dislocation) & 54 & 02.50 \\
Soft tissue (Muscle \& or tendon) injury & 378 & 17.60 \\
Orthopedic + Soft tissue injury & 1331 & 60.58 \\
Nerve injury & 337 & 15.70 \\
Abdominal organs & 6 & 00.30 \\
Head injury & 72 & 03.32 \\
\hline
\end{tabular}

Table-IV

Time elapsed from injury to vascular procedures $(n-1630)$

\begin{tabular}{lcc}
\hline Injury Time & Number of Patients & Percentage \\
\hline$<06$ & 720 & 44.17 \\
$07-12$ & 436 & 26.76 \\
$13-24$ & 362 & 22.25 \\
$>24$ & 112 & 06.82 \\
\hline
\end{tabular}

Table-V

Vascular procedures done $(n=1630)$

\begin{tabular}{lcc}
\hline Procedure & $\begin{array}{c}\text { Number of } \\
\text { Patients }\end{array}$ & Percentage \\
\hline End to end anastomosis & 453 & 27.79 \\
Autologous vein interposition/patch & 691 & 42.39 \\
PTFE graft & 58 & 03.57 \\
Ligation of bleeding vessel & 371 & 22.79 \\
Vessel release & 56 & 03.46 \\
\hline
\end{tabular}

Table-VI

Postoperative complications after vascular procedure $(n=548)$.

\begin{tabular}{lcc}
\hline Complications & $\begin{array}{c}\text { Number of } \\
\text { Patients }\end{array}$ & Percentage \\
\hline Wound infection & 452 & 82.48 \\
Compartment syndrome & 09 & 01.64 \\
Graft thrombosis & 47 & 08.58 \\
Hemorrhage & 17 & 03.10 \\
Renal failure & 13 & 02.37 \\
Respiratory failure & 07 & 01.28 \\
Cerebrovascular accident & 03 & 00.55 \\
\hline
\end{tabular}




\section{Discussion}

Vascular trauma involves injury to artery or vein or both. Among the vascular injuries arterial injury are more challenging condition in surgical practice. Venous injuries can cause bleeding profusely \& may be complicated by air embolism particularly when the central veins are involved. Thin wall of veins make them difficult to handle. Control of hemorrhage and restoration of perfusion are key to the resolution of vascular injury. When patients fail to reach the specialist in time many of them end up with losing limbs or livcs. ${ }^{10,11}$

Vascular surgery is a specialty of surgery in which diseases of the vascular system are managed by medical therapy, catheter procedures and surgical reconstruction. As many as $50 \%$ of patients with vascular disease present urgently or as an emergency and in the past often been managed by general surgeons. Training programs in vascular surgery are slightly different in different parts of the world ranging from 1-6 years. ${ }^{9}$ In Bangladesh post graduate students in general surgery as well as some other specialties like orthopedic \& plastic surgery are either not exposed or if exposed then only for a relatively short time (1-3 months) to vascular surgery training. This period is very short for the candidate to grasp the decisionmaking and technical skill of vascular surgery.

It is needed to focus on common emergencies like acute limb ischemia due to vascular injury as well as abdominal vascular injuries. All trauma surgeons should be able to make an early diagnosis of 'vascular injuries on clinical bases, order and use bed-side procedures like portable Doppler examination, start an effective initial management to stop bleeding, treat shock and stabilize fractures \&/or dislocations and initiate definitive management to repair the vessels or if not capable to do so then refer the patient to a vascular surgical centre as soon as possible. ${ }^{9}$

In our study it shows vascular injury occurred mostly in male young persons. It is because male young persons are more active and mobile in the society. Similar results were found in other studies. ${ }^{10.12 .13}$ In majority of the cases vascular injury was caused by RTA. This finding is consistent with some studies ${ }^{24.14}$ but not with some other studies 3.5 .15 in western world. Higher percentage of patients with RTA in our study reflects increased mobilization of people by the use of vehicle with the pace of industrialization and urbanization in the developing economy of the country. Relatively more cases with assault in western countries coincide with the level of domestic and civil violence's of those countries. In our study lower limb vessels injury was more common in comparison to upper limb or abdominal vessels. Among the lower limb vessels political artery injury was the most common site of injury. These findings are consistent with some similar studies. Among the associated injuries orthopedic \& soft tissues injuries were most common as it showed in some other studies. Associated injuries are important factors for the outcome specially rate of amputation (in case of limb vessel injury) \& mortality of vascular trauma victims. Majority of the patients presented after the golden period of six hours following trauma, so vascular procedures were done after 6 hours in majority of the cases. This finding is consistent with some studies) Time of presentation is an important prognostic marker of limb salvage and overall survival. Again vascular procedures were not done immediately after arrival at the hospital due to referral of some patients to other hospitals because of unavailability of orthopedic, neuro \& general surgeons for stabilization of associated major fractures and management of life saving conditions like acute abdomen \&/or head injuries as priority basis. These reflects countrywide hick of availability of effective ambulatory services, vascular expertise and trauma team with consequent deficiencies in trauma management. Our study hospital is a tertiary level hospital for vascular care but here there is no trauma team.

Satisfactory outcomes after trauma require the practiced, coordinated action of doctors from different specialties, nurses $\&$ radiographers. A team approach is required to achieve smooth resuscitation. The trauma team should have a leader responsibly for co-ordination and at least one member should be a trained general surgeon.

Among the vascular procedures autologous reverse vein graft were in majority of the cases followed by end to end anastomosis. This finding is consistent with some studies. Number of patients needed fasciotomy in our study is consistent with some other studies. Prophylactic ally fasciotomy should be done in patients with delayed presentation \& low threshold for the procedure to reduce the risk of adverse limb outcomes. In patients with delayed fasciotomics had double the rate of major amputation and threefold the rate of mortality. Following vascular procedures $33.62 \%$ patients developed post-operative complications. Among the complications wound infection was commonest followed by graft thrombosis, hemorrhage, renal failure, compartment syndrome, respiratory failure \& ccrcbrovascular accidents. These findings also mimics with an another study.

In case of extremity vascular injury limb salvage rate $(64.60 \%)$ of our study is consistent with some studies in developing countries. Multiple factors are involved in the 
prognosis of affected limb following traumatic vascular injury. Among the factors- delayed presentation \& time elapsed before vascular procedures and associated injury mostly soft tissue deficits are important. High rate $(35.40 \%)$ of amputation of our study reflects delayed presentation of patients \& time elapsed after referral to other hospitals for priority management of associated injuries in some cases. Amputation after vascular procedures were advised for failed repair, graft thrombosis, sepsis, renal failure \& inadequate soft tissue coverage of affected limb. Mortality of our study could not assessed as some of the patients referred to other hospitals for associated injuries did not came back and those patients referred to other hospitals after vascular procedures for management of complications were not followed up.

\section{Conclusion:}

In developing countries like us vascular injury is a major public health problem. Most ours of the victims are young males in their productive life period and road traffic accidents are the most common cause. Lack of availability of vascular specialist along with delayed presentation are major contributors of high rate of limb loss. Doctors should be encouraged to become vascular surgeon. Vascular surgeons should be available in trauma centers and at least one general surgeon should be available in a vascular center. Till the availability of vascular surgeons, the general as well as the orthopedic surgeons should be adequately trained and have a good expertise in vascular surgery to deal with emergency cases of vascular trauma in extremities \&/or abdomen to save life and limbs of vascular trauma victims. Improvement in educational, socioeconomic \& awareness condition of people and implementation of road safety measures are important for the prevention of injury.

\section{Conflict of interest:}

There are no conflicts of interest.

\section{References:}

1. Ryan JM. Accident and emergency surgery in Bailey \& Love's Short Practice of Surgery,23 Amold,338 Euston Road, London NW I 3BH,2000;270-80.

2. Rich NM, Rhee P. A historical tour of vascular injury from inception to the new millennium. Surg Clin North Am $2001 ; 81: 1199-15$.

3. Felicino DV, Moore FA, Moore EE, ci al. Evaluation and management of peripheral vascular injury. Part 1. Western Trauma Association/Critical I)ecisions in Trauma. J Trauma 201 1;70:1551-56.
4. Mcnakuru SR. Behera A, Jindal R, Kaman L, Dolcy $R$, Venkatcsan R. Extremity vascular trauma in civilian population: a seven year review from north India. Injury 2005;36:400-06.

5. DuBosc JJ. Savage SA, Fabian IC. Menaker J, Scalca T, I lolcomb JB, et al. The American Association for the Surgery of Trauma Prospective Observational Vascular Injury Treatment (PROOVIT) registry: multicenter data on modern vascular injury diagnosis, management and outcomes. J Trauma Acute Care Surg 201 5;78(2):2 15-22.

6. Jaipuria J, Sagar S. Singhal M, I3agdia A, Gupta A, Kumar $S$, et al. Pediatric extremity vascular injuries - experience from a large urban trauma center in India. Injury 201 4;45( I): 176-82.

7. Murad M, Eweda A, Abdel-Moamen II, Hussein M, Elsaghir M. Vascular trauma and its management: one and a half years atler the 25th January revolution. Journal of the Arab Society for Medical Research 2013:8:43-47.

8. Taha ÀY. Vascular Injurics in Basra, Iraq: A 5-Year Expcricncc. 11e Journal of the Arab Board of Medical Specializations 2004;6:I 18-25.

9. Sunil SJ. Peripheral Arterial Injuries: an Indian Experience. Springer 2015; DOI: I 0.1007/s1226201 5-1337-1.

10. Taha ÀY. Extremity Vascular Injuries. School of Medicine, University of Sulaimaniyah. 2014: htipsl/ sulaimaniu.academ ia.edulAbdulsalamTaha.

11. Taha YA. Vascular Surgery and the General Surgeon: Review Article. International Journal of Clinical Medicine 201 5;6: 132-43.

12. Sah B, Shrestha KG, Tiwary KK, Rcddy J. Analysis of Consecutive Cases of Vascular Injury in Tertiary Level hospital in Central Nepal. Journal of College of Medical Sciences- Nepal 201 7;13(3):357-62.

13. Nonga NB, Savorn EP, Bang GA, Londji GM, Essomba AG. Difficulties in the Management of Civilian Peripheral Vascular Trauma and their Complications at the University Teaching I lospital of Yaound'c, Cameroon. J Vase Mcd Surg 2016;4:292. DOI: 10.4172/2329-6925.1000292.

14. Friend J, Rao S. Sicunaraine K: ct al. Vascular trauma in Australia - a comparison of two studies over 15 years. ANZ Surg 2013; [)O1: 10.111 1/ anz.12309. 
15. Perkins ZB, De'Ath HD, Aylwin C, Brohi K, Walsh M, Tai NR. Epidemiology and outcome of vascular trauma at a British Major Trauma Centre. Eur J Vase Endovasc Surg 201 2;44(2):203-09.

16. Fingerhut A, Lcppanicmi AK, Androulakis GA, Archodovassilis F, Bouillon B, Cavina E, et al. The European experience with vascular injuries. Surg Clin North Am 2002:82(1 ):175-88.

17. MeNamara ii. Bicf I)K. Streinpic ii:. Wright JK. Management of' fracture with associated arterial injury in combat casualties. J Trauma 1973;|3(i):1719.

18. Dcsai P. Audige L, Suk M. Combined orthopedic and vascular lower extremity injuries: sequence of care and outcomes. Am J Orthop 2012;41(4):18286.

19. Ain OM, Redmond HP, Burke P13, Grace PA, Bouchier-Hayes DB. Vascular Trauma - a review. JAm Coil Surg 1995;181(1):91-108.

20. Fox N, Rajani RR, Bokhari F, Chiu WC, Kerwin A, Seamon Mi, Ct al. Eastern Association for the Surgery of Trauma. Evaluation and management of penetrating lower extremity arterial trauma: An Eastern Association hr the Surgery of Trauma practice management guideline. I Trauma Acute Care Surg 2012;73(5):315-20.

21. Siddique ML Bhatti AM. A two-year experience of treating vascular trauma in the extremities in a military hospital. J Pak Mcd Assoc 2013;63(3):32730.

22. Klockcr J, Falkensammer J, Peliegrini L, Biehl M. Tauscher T, Fraedrich G. Repair of arterial injury aflcr blunt trauma in the upper extremity immediate and long term outcome. Fur J Vase Endovasc Surg 201 0;39(2): 160-64.

23. Farber A, Tan TW. I larnburg NM, Kalish JA, et al. Early fasciotomy in patients with extremity vascular injury is associated with decreased risk of adverse limb outcomes: a review of the National Trauma Data Bank. Injury 2012;43(9):1486-91.

24. Farros D.souza AA. Rationale for temporary arterial and venous shunting in the management of limb vascular injuries. Eur J Vase Endovasc Surg 1989;3:471-74

25. Moniz MP, Ombrellaro MP, Stevens SL, Freeman MB, Diamond DL, Goldman MH. Concomitant orthopedic and vascular injuries as predictors for limb loss in blunt lower extremity trauma. Am Surg 1997;63(I):24-28.

26. Razmadzc A. Vascular injuries of the limbs: a liilccn year Georgian cxpcricncc. Euri Vase lindovasc Surg 1999;18(3):233-35.

27. Hafez HM, Wodgar J. Robbs JV. Lower extremity arterial injury: results of 550 cases and review of risk factors associated with limb loss. J Vase Surg 2001;33:1212-19.

28. Frykbcrg ER. Combined Vascular and Skeletal Trauma 2013. http//www.traurna.orglarchive/ vascular/vascskeletal.html.

29. Khan FI 1. Yousuf KM, Bagwani AR. Vascular injuries of the extremities are a major challenge in a third world country. Journal of Trauma Management \& Outcomes 2015; DOI: 10.1 186/s13032-0150027-0. 